\title{
Social Security as the Basis of the National Security of the Country and the Region
}

\author{
Irina Logvinova and Natalya Gorkovenko* \\ Rostov State Transport University, Rostov-on-Don, Russia
}

\begin{abstract}
The article examines the phenomena of «security» and «social security» from philosophical, sociological and psychological perspectives. The analysis of domestic and foreign scientific literature on security issues undertaken by the authors of the article showed that solving the problems of ensuring social security of an individual and society as a whole involves the interdisciplinary integration of scientific knowledge (including in the field of pedagogy and education), which will allow us to develop practical recommendations for preventing the destruction of social systems. Based on the synthesis of the content of analytical reports and monitoring studies on security issues of the leading sociological centers of Russia and the materials of international expert organizations, in particular UN documents, indicators, indicators of the level of security and methods of their assessment are identified. The applied significance of the theoretical and methodological work lies in the search for models of functioning and management of systems for ensuring the security of the individual and society at all levels of social existence and life activity that are adequate to modern conditions.
\end{abstract}

\section{Introduction}

At the present stage of the development of the state, its main task is to maintain the social and economic security of the regions and the country as a whole. That is why it is so important to ensure the sustainable socio-economic development of the regions, which can be achieved through timely identification of threats to the social sphere and their assessment. At all times, social security has been an integral part of the national security of the State. Now the question of how to ensure social security is particularly acute for each country [1]. In turn, national security can be divided into the following components::

- economic security;

- social security;

- health safety;

- personal safety of a person;

- food security;

- public safety;

- political security.

*Corresponding author : natalya_g2010@mail.ru 
All of the above components interact with each other and are part of a single system, so we can say that the concept of social security includes the fight against poverty, crime, the protection of jobs, income, health security and the preservation of the environment.

Social security can be defined as the interaction of various social strata and groups in society on the principles of partnership, which ensures sustainable development and sociopolitical unity of society and the state and interaction with other states [2].

\section{Methods}

To ensure social security, special mechanisms are needed that combine all the processes taking place in the socio-economic sphere. The social security mechanism is a system of organizational, economic and legal measures to prevent socio-economic threats.

Elements of the social security mechanism:

- monitoring of the economy and society, conducted to identify and predict external and internal threats to society;

- development of normative values for socio-economic indicators. Non-compliance with the limit values leads to instability and social conflicts;

- legal regulation of the state in the social sphere.

At the same time, we should not forget that over time, threats to society are constantly changing and largely depend on the economic situation, the reforms carried out, the political situation in the country, etc., which means that the mechanism for ensuring social security is adaptive.

Any mechanism can work effectively if certain principles of its operation are observed:

- complexity — takes into account all factors that affect the state of security;

- systematic - constant consideration of all forms of the socio-economic sphere, both external and internal;

- variability - identification of several options for resolving socio-economic development;

- acceptable risk - implementation of available measures aimed at protecting people in the market environment and preventing them from exceeding the threshold values.

Based on these principles, it is advisable to consider the mechanism of social security by levels:

- strategic level. The mechanism works at this level to eliminate social contradictions. The level is characterized by the development of system-forming socio-economic decisions, which are reflected in strategies and programs to ensure social security;

- tactical level. The mechanism consists in solving tasks that are related to eliminating specific threats or preventing their impact on the social sphere;

- operational level. At this level, the social security mechanism works to eliminate the consequences of threats and negative impacts.

The presented level gradation of the mechanism of ensuring social security is also reflected in the system of ensuring the security of the state. This relationship between the mechanism and the system is expressed in the development of a security policy, concept, and national security strategy. Thus, the process of ensuring social security develops into ensuring economic and national security.

Of course, the mechanism of ensuring social security alone will not allow us to fully assess all the emerging threats. Special methods are used for such purposes.

The main methods that are used to assess threats in the socio-economic sphere are:

- statistical and mathematical method;

- analytical method;

- comparison method. 
The statistical-mathematical method is the study of official statistics, its analysis and calculation of the necessary indicators. The analytical method is based on identifying the nature of threats, determining the causes of their occurrence and the consequences of these threats. The method of comparison is to compare the indicators of the crisis elements of the social sphere in one region with the indicators of other regions and the country as a whole. To increase the level of threat assessment, it is recommended to use all methods in a comprehensive manner.

\section{Results}

The threat of population poverty is the prevailing threat in the system of ensuring national security and requires the formation of a comprehensive policy to overcome poverty both at the national level and in the regional context.

The main directions and mechanisms of the regional poverty reduction policy model are presented in the figure 1.

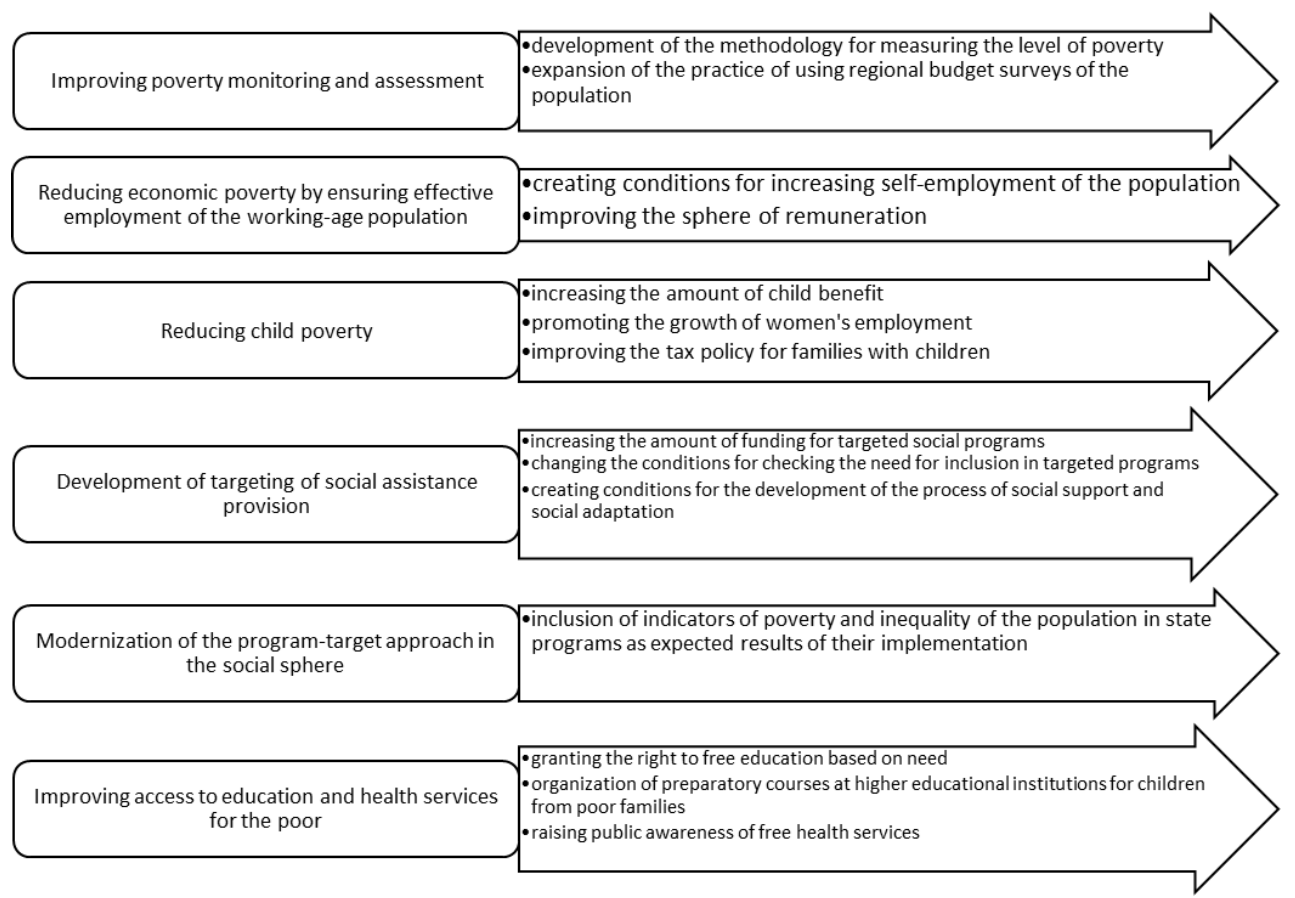

Fig. 1. The main directions and mechanisms of formation of the regional policy of overcoming poverty

In the model of regional policy to overcome poverty, it is important to correctly determine the directions of the policy.

The direction "Improving poverty monitoring and assessment" implies two mechanisms for reducing poverty in the region.

The first mechanism is the development of a methodology for measuring the level of poverty, which involves the creation of an integral indicator of overcoming poverty. The integral indicator should include a wide range of statistical indicators of socio-economic development. Thanks to this indicator, it will be possible to assess the effectiveness of decisions taken to reduce the level of poverty and monitor the effectiveness of measures aimed at overcoming poverty. 
The list of indicators of regional budget surveys should be expanded to include in the integral indicator, among such indicators it is necessary to note:

- indicators of relative poverty (for example, at the level of $50 \%$ of the average per capita income);

- indicators of the effectiveness of targeted social assistance (the number of poor people covered by targeted social programs);

- assessment of the level of child poverty (access to education and child health services);

- assessment of non-monetary aspects of poverty (living conditions, access to social services, health and education services);

In addition to all the above, budget surveys should be aimed at recognizing the risk factors of poverty and identifying their impact on the development of poverty.

The second direction of the regional policy model is "reducing economic poverty by ensuring effective employment of the working-age population", which involves the use of such measures as: creating conditions for self-employment of the population through the development of small businesses and improving the sphere of remuneration.

Measures to employ the working-age population are aimed at developing small businesses and attracting young people to this sector of the economy. To do this, it is necessary to improve the system of concessional lending, on the terms of low interest rates, simplify collateral, and develop public-private cooperation in order to minimize business risks. The development of small businesses can take place in such areas as:

- preschool education (opening of private kindergartens);

- career guidance and creative activities (opening rehabilitation centers for children and adolescents with disabilities);

- sports and tourism (opening gyms, swimming pools, creating tourist routes);

- ecology (enterprises for street cleaning and processing of non-decomposable garbage).

Improving wages in order to reduce the level of poverty is made possible by the conclusion of long-term employment contracts, the formation of a system of incentives for the implementation of work plans, employee initiatives and the quality of work.

The policy of "reducing child poverty" involves the use of mechanisms to increase child benefits, increase the employment of women and improve the tax policy for families with children.

An increase in child benefits is necessary to reduce child poverty. To this end, it is proposed to provide benefits not only for families with incomes below the subsistence minimum, but also with incomes equal to or below 1.5-2 subsistence minimums. This measure will help families with children to avoid the risk of falling into the poor.

An important role in reducing child poverty is played by measures to increase the labor activity of women and their professional training. As a rule, women are discriminated against in the labor market. To eliminate this threat, it is necessary to provide employers who employ women with young children with benefits of various types and directions. In order to support unemployed women with children, the employment centers of the Rostov region need to create a list of jobs with a greater focus on this category of unemployed, and also need to create on a permanent basis courses for improving skills and acquiring new skills for unemployed women [3].

In addition, an important area is the improvement of tax benefits for families with children, not only at the regional level, but also at the federal level. This direction involves the establishment of deductions for families with children on personal income tax in the amount of the subsistence minimum, as well as the exemption of large families from paying transport tax.

Regional policies to overcome poverty cannot do without increasing the effectiveness of targeted social assistance. To achieve this goal, it is necessary to increase funding for targeted social programs, change the conditions for checking the need for inclusion in 
targeted programs, and create conditions for the development of the process of social support and social adaptation [4].

The increase in monetary assistance to poor citizens will be possible due to the increase in the importance of targeted programs in the total social expenditures of the consolidated budget of the region. At the moment, in the system of social benefits, priority is given to certain categories of citizens and people of retirement age. An increase in the amount of financial assistance in the framework of targeted social programs [5], child allowances and subsidies for housing and communal services is possible only by reducing the expenditure of budget funds to support certain categories of citizens. The reduction of budget resources in relation to certain categories of citizens can be carried out with the help of:

- cancellation of benefits;

- cancellation of benefits for new recipients with the continuation of the provision of benefits to citizens who already use them;

- providing benefits only to those citizens whose income does not exceed 1.5 subsistence minimum [6].

Improving the conditions for checking the need for social assistance is a priority, since often non-poor residents of the Rostov region use social assistance. To accomplish this task, it is possible to introduce a point system of need for targeted social assistance, which will be based on such criteria by which a citizen who has asked for help can independently improve their well-being.

To improve the targeting of social assistance provided on the basis of the contract, it is necessary to create conditions for social support of social adaptation contracts. This mechanism includes training of specialists in social support of social adaptation contracts, which is aimed at gaining knowledge in the field of legislation related to the registration of individual business activities, as well as the development of guidelines and instructions that specify the stages of social support of contracts.

The implementation of the direction of "modernization of the program-target approach", which includes the inclusion of indicators of poverty and inequality of the population in the state programs of the Rostov region as the expected results of their implementation, is necessary because the program-target approach is an effective method of managing the socio-economic development of the region. The target orientation of state programs can be:

- reducing the share of the population with incomes below the subsistence minimum;

- reduction of the decile coefficient;

- increase in the share of employed poor citizens in the total number of poor people;

- increase in the share of the poor who received support for the organization and development of entrepreneurship.

The latter direction in the model of regional policy for overcoming poverty involves increasing the availability of health and education services for the poor. Currently, access to free education can be obtained with high grades and a high score on the unified state exam, but it is necessary to make the best graduates from poor families priority candidates for free education [7]. There is also a need to create preparatory courses for gifted children from poor families on the basis of higher educational institutions.

\section{Conclusions}

Creating a regional policy to reduce the threat of poverty. When implementing the proposed regional policy, the executive authorities of the Rostov region will observe a stable reduction in poverty, inequality in the distribution of income of the population, as well as socio-economic development of the region [8].

In addition to the mentioned directions in the policy of overcoming poverty, it is necessary to add the importance of covering the problem of poverty in the mass media and 
the Internet as the main social problem. The results of research on this problem should be made publicly available to a wide audience, as an effective way to combat this threat to socio-economic security. When implementing all the measures of the presented model of regional policy, the executive authorities will observe a stable reduction in poverty, inequality in the distribution of income of the population, as well as the socio-economic development of the region.

\section{References}

1. Zhigunova A.V., Nemova Yu. V. Monitoring of economic security, In the collection: The Constitution of the Russian Federation as a Guarantor of Human and Civil Rights and Freedoms. Materials of the Second All-Russian National Scientific and Practical Conference. pp. 189-192. (2019).

2. Goncharova P. Yu., Logvinova I. V. Threats to economic security in the social sphere, № 3 (45), P. 53. (2020).

3. Logvinova I. V., Arkhipova Ya. V. Legal protection of citizens from unemployment in modern conditions, In the collection: The Constitution of the Russian Federation as a Guarantor of Human and Civil Rights and Freedoms. materials of the All-Russian National Scientific and Practical Conference. Rostov State University of Railway Transport. pp. 207-212. (2019).

4. Gorkovenko N. A., Kim S. A. Demographic crisis as a factor influencing economic security, In the collection: Economic and legal mechanisms for ensuring national security, Materials of the Third All-Russian National Scientific and Practical Conference. pp. 26-29. (2019).

5. Kashnik O. I., Bryzgalina A. A. Social security: theoretical aspects, Obrazovanie i nauka, № 3 (102), p.98-110 (2013).

6. Sadykova N. R. Characteristic of the main components of social security of the individual, Modern scientific research and innovation, No. 6, Part 5 (2015).

7. Podolskaya E. A., Nazarkina V. N. Social security: the essence, threats and ways to ensure, Sociological research, No. 11, pp. 133-139 (2016).

8. Shevkunov N., Zigunova A., Logvinova I., Gorkovenko N., Kravchenko L., Gromakova N. Formation of spiritual and moral ideology and methodology of innovative economic development, E3S Web of Conferences. Innovative technologies in Environmental Science and Education, ITESE 2019. p. 01104. (2019). 